\title{
Exercise testing in the preoperative evaluation of patients with bronchogenic carcinoma
}

\author{
K. Richter Larsen*, U.G. Svendsen*, N. Milman*, J. Brenøe**, B.N. Petersen*
}

Exercise testing in the preoperative evaluation of patients with bronchogenic carcinoma. K. Richter Larsen, U.G. Svendsen, N. Milman, J. Brenфe, B.N. Petersen. CERS Journals Ltd 1997.

ABSTRACT: The aim of this study was to evaluate which parameters of preoperative spirometry and cardiopulmonary exercise test are the best predictors of postoperative morbidity and mortality in patients with bronchogenic carcinoma.

Ninety seven patients were prospectively and consecutively examined. All patients had preoperative maximal exercise test and dynamic spirometry. Postoperative complications and causes of death were registered. Logistic regression was used and models explaining the relationship between preoperative variables and postoperative complications and deaths were constructed.

We found significant differences in preoperative maximal workload and carbon dioxide output between groups, with and without cardiopulmonary-related complications, but not in spirometry variables. Logistic regression showed maximal workload to be the only predictor of cardiopulmonary complications. Maximal oxygen uptake was predictive of cardiopulmonary deaths. Maximal oxygen uptake and forced expiratory volume were predictive of postoperative complications. A maximal oxygen uptake $<\mathbf{5 0 \%}$ predicted was associated with high risk of death from cardiopulmonary causes. Kaplan-Meier survival curves showed that maximal oxygen uptake was correlated to long-term survival, while spirometric variables were not.

Exercise testing can be used in the preoperative evaluation of patients with nonmetastatic bronchogenic carcinoma. A combination of the results of variables from spirometry and exercise testing is proposed to be used as a preoperative criterion for operability.

Eur Respir J 1997; 10: 1559-1565.
*Dept of Pulmonary Medicine and **Dept of Thoracic and Heart Surgery, Gentofte Hospital, University of Copenhagen, Denmark.

Correspondence: K. Richter Larsen Fossgårdsvej 34

DK-2720 Vanløse

Denmark

Keywords: Bronchogenic carcinoma exercise test

lung neoplasms surgery operability

operative mortality

postoperative complications

Received: July 301996

Accepted after revision March 211997

This study was supported by grants from Velux, Foersom, and Hartmanns Foundations, Denmark.
Carcinoma of the lung is one of the most common causes of death due to cancer in men, and is increasingly common in women. Some 900,000 new cases are reported worldwide every year [1]. The prognosis in untreated cases is poor, and at present the major curative treatment modality for non-small cell carcinoma is resection. The removal of lung parenchyma from patients, who are usually smokers with compromised cardiovascular or pulmonary status, may lead to cardiopulmonary failure or death. Many variables have been used to assess the risk of postoperative complications, but it is not clear which of these parameters in preoperative pulmonary function testing are the best predictors of the operative outcome. Many centres recommend operation without additional testing in patients with a forced expiratory volume in one second (FEV1) $>2.0 \mathrm{~L}$ or $60 \%$ of predicted and a diffusing capacity $>60 \%$ pred [2-6]. If these requirements are not met, a perfusion or ventilation scan is performed, and the predicted postoperative FEV1 (FEV1,ppo) is estimated. The accuracy of these methods is proven [7-11] and it seems generally accepted that a FEV1,ppo of $0.8-1.0 \mathrm{~L}$ or $30 \%$ pred represents the lower limits of acceptable risk [4-6, 12-17]. Some recommend different limits for different resections [18]. In spite of this consensus for identifying patients at risk, about $30 \%$ develop cardiopulmonary complications with a 30 day mortality of $0.6-5 \%$ [18-20], depending on the surgical procedure.

Both the respiratory and cardiovascular systems are under stress during physical exercise because of the oxygen requirement of working muscles, and carbon dioxide is produced. An increase in this gas exchange implies a close coupling of pulmonary ventilation and cardiovascular circulation. The conditions during hard physical work resemble the situation after lung resection, and the exercise stress test is, therefore, theoretically useful in the preoperative evaluation of patients with lung cancer. There has been debate about the clinical significance of exercise testing in preoperative evaluation, and there are conflicting results from the literature concerning the applicability of a symptom-limited exercise test. Some papers advocate the exercise test as a good predictor of postoperative complications [16, 19, 21-26] and others do not [12, 27-29]. The studies differ in design, number of participating patients, registration of complications and statistical methods.

The purpose of this investigation was to study the value of the cardiopulmonary exercise test and pulmonary function test in predicting postoperative morbidity, and mortality in patients scheduled for lung resection with 
nonmetastatic bronchogenic carcinoma. Parameters were analysed as absolute values and related to weight and predicted normal values.

\section{Materials and methods}

\section{Study subjects}

The study was approved by the local Ethics Committee and informed consent was obtained from all subjects. Over a period of 32 months all patients with proven or suspected lung malignancy for lung resection were included. Patients were excluded if they: were unable to complete a maximal ergometer exercise test due to immobilization or severe pain from thorax or joints; had severe ischaemic heart disease; had coronary arterial by-pass grafting or valvular surgery; or were receiving betaadrenergic antagonists. Four hundred and seventy three patients were diagnosed with bronchogenic carcinoma and 91 were clinically highly likely to have malignancy, although there was no histological evidence. Of 158 operable patients, 61 were excluded for the following reasons: 10 proved to have a nonmalignant diagnosis; 12 were qualified to perform an exercise test, but did not wish to participate, mostly for psychological reasons; 10 were not considered able to complete a maximal ergometer exercise test because of weakness and pain; 10 had severe ischaemic heart disease, coronary artery bypass grafting or valvular surgery; six suffered from paraneoplastic myalgia; four were treated with beta-adrenergic antagonists; two had venous lower limb thrombosis; one had thyrotoxicosis; and six were operated on before inclusion in the trial.

\section{Study design}

All patients for lung resection were prospectively and consecutively examined with a maximal ramp exercise test, spirometry, arterial gas tensions at rest, and, for patients with a FEV1 $<2.0 \mathrm{~L}$, a pulmonary perfusion scan was performed. Predefined operative and postoperative complications, and 30 day mortality were registered. Preoperative data were analysed for predictability of postoperative morbidity and mortality.

\section{Methods}

Patients were considered operable if FEV1 was $>2.0$ L or FEV1,ppo was $>1.0$ L. FEV1,ppo was estimated on the basis of perfusion scanning [4, 14]. The surgical staff were blinded to the data from the exercise tests, which were not used in the assessment of physiological operability.

Exercise test. A multistage ramp, $10-15 \mathrm{~W} \cdot \mathrm{min}^{-1}$ maximal exercise protocol was performed in the upright position on an electrically braked cycle ergometer (Medgraphics CPE 2000®; Medical Graphics Corporation, Minnesota, MN, USA). Subjects breathed through a lowresistance, low dead-space (100 mL) valve (Hans Rudolph®, Kansas City, USA). The following variables were determined throughout the test: work rate (WR; in W), oxygen uptake per minute $\left(V^{\prime} \mathrm{O}_{2}\right.$; in $\mathrm{mL} \cdot \mathrm{min}^{-1}$ at standard temperature and pressure in the absence of water vapour
(STPD), carbon dioxide production $\left(V^{\prime} \mathrm{CO}_{2}\right.$; in $\mathrm{mL} \cdot \mathrm{min}^{-1}$ at STPD), minute ventilation ( $V^{\prime} \mathrm{E}$; in $\mathrm{L}$ at body temperature and ambient pressure, saturated with water vapour $(\mathrm{BTPS}))$, cardiac frequency $\left(f_{\mathrm{C}}\right.$; in beats $\left.\cdot \mathrm{min}^{-1}\right)$, capillary saturation $\left(\mathrm{SC}_{\mathrm{O}} \mathrm{O}_{2}\right.$; as a percentage) (Radiometer, Copenhagen, Denmark) and blood pressure $(\mathrm{mmHg})$.

All patients were monitored with a 12-lead electrocardiogram (ECG) during exercise tests. Hard copies were produced at rest, every minute during work, at maximum exercise, and when arrhythmias or other ECG changes occurred. Anaerobic threshold (AT) corresponding to the maximum $V^{\prime} \mathrm{O}_{2}\left(V^{\prime} \mathrm{O}_{2}\right.$,max; in $\left.\mathrm{mL} \cdot \mathrm{min}^{-1}\right)$ was estimated by the $\mathrm{V}$-slope method [30]. The respiratory gas exchange variables were determined on line using a computer-controlled system (Medical Graphics Corporation 2001, MN, USA) with the cycle ergometer interfaced to the computer with constant feedback on the power output. Data were automatically collected breathby-breath and the average of eight breaths was reported. Results were compared with predicted values [31].

Patients were asked to refrain from heavy work, smoking and drinking coffee or tea on the day of exercise test. Patients exercised to exhaustion, or to occurrence of predefined criteria for termination of the test: severe angina pectoris; systolic blood pressure $>240 \mathrm{mmHg}$; or blood pressure drop $>20 \mathrm{mmHg}, \mathrm{SC}, \mathrm{O}_{2}<80 \%$ [32]. Confirmation of maximal exercise was assessed by failure of $V^{\prime} \mathrm{O}_{2}$ to rise in spite of further increase in work rate and by a respiratory exchange ratio $\left(V^{\prime} \mathrm{CO}_{2} / V^{\prime} \mathrm{O}_{2}\right)>1.09$ [32]. The pneumotachograph and gas analysers were calibrated before each test. The relative humidity, ambient temperature and barometric pressure were registered and entered. The pneumotachograph was calibrated against a 3.0 L syringe (Hans Rudolph 5530). Gas analysers were calibrated as a two point calibration against a commercially available gas mixture (14.0\% oxygen, $6.0 \%$ carbon dioxide) and ambient air.

Resting lung function. FEV1, vital capacity (VC), and forced vital capacity (FVC) were measured (Vitalograph ${ }^{\circledR}$, Buckingham, UK). All values obtained were also expressed as percentages of predicted values using standardized prediction formulae [33].

Arterial blood gas analysis. Arterial blood at rest was analysed for oxygen and carbon dioxide tensions $\left(\mathrm{Pa}_{\mathrm{a}} \mathrm{O}_{2}\right.$, $P \mathrm{a}, \mathrm{CO}_{2}$, respectively) (ABL4®; Radiometer, Copenhagen, Denmark).

Complications. Complications were defined as postoperative when they occurred within 30 days after resection. Complications resulting from both poor cardiopulmonary function and from more technical problems were recorded.

Cardiopulmonary complications were defined as: 1) prolonged mechanical ventilation $(>48 \mathrm{~h}) ; 2$ ) respiratory insufficiency $\left(\mathrm{Pa}_{\mathrm{a}} \mathrm{CO}_{2}>65 \mathrm{mmHg}\right.$ or $\mathrm{Pa}, \mathrm{O}_{2}<55 \mathrm{mmHg}$, without oxygen supply; 3 ) lobar atelectasis on radiography; 4) myocardial infarction verified by rise in enzymes; 5) cardiac arrhythmias requiring therapy; 6) pneumonia (temperatures $>38^{\circ} \mathrm{C}$, increased white cell counts, infiltrate on radiographs); 7) heart failure requiring therapy; and 8) death caused by respiratory insufficiency or heart failure. 
Technical-related complications were defined as: 1) empyema; 2) wound infections; 3 ) leak of the bronchus stump; 4) bronchopleural fistula (air leak for $>1$ week); and 5) blood loss requiring transfusion.

The patients with complications were classified into two groups: $\mathrm{C1}(\mathrm{n}=59)$, patients with one or more of any of the above-mentioned cardiopulmonary and technical complications, or deaths from any cause within 30 days; and C2 $(n=31)$, patients with one or more (fatal or not) of the following events: respiratory insufficiency; prolonged mechanical ventilation; heart failure; myocardial infarction; pneumonia; or lobar atelectasis. This classification was performed to separate the complications that were found to be related to cardiopulmonary function $(\mathrm{C} 2)$ from the complications that were more related to technical procedures $(\mathrm{C} 1)$.

\section{Statistical analysis}

Groups were analysed for confounders by Fisher's exact test. Correlations between preoperative parameters were studied with Spearman's rank correlation test. Differences in spirometry and exercise test variables between groups, with or without complications, were analysed by two sample rank sum test (Mann-Whitney). Logistic regression (SAS/STAT®, version 6.4, vol. 2; SAS Institute Inc., Cary, NC, USA; forward selection, $\mathrm{p}<0.05$ to enter model) was used to test for predictability of preoperative parameters from spirometry and exercise test, either individually or in combination. End-points were development of cardiopulmonary and technicalrelated complications, and cases of cardiopulmonaryrelated deaths. Stepwise logistic regression was used to construct a model that could account for the observed variation with the greatest accuracy [34]. Fisher's exact test (fourfold table) was used to define the best cut-off limit (xlim) of different variables (table 1). The diagnostic gain in the preoperative evaluation, by using a given cut-off limit, was defined as $\mathrm{A} /(\mathrm{A}+\mathrm{B})-\mathrm{C} /(\mathrm{C}+\mathrm{D})$ (table 1) and sensitivity and specificity were determined. The influence of different variables on survival was analysed by the Kaplan-Meier and log-rank methods. A p-value of less than 0.05 was accepted as statistically significant for all analyses.

\section{Results}

Ninety seven patients were investigated preoperatively with a maximal exercise test. Twenty seven patients had pneumonectomy, 52 had lobectomy, including 10 bilobectomies, and 18 patients had explorative thoracotomy without lung resection. Forty five per cent had squamous cell carcinoma, 34\% had adenocarcinoma, $6 \%$ had large-cell carcinoma and $7 \%$ had other types. Of the resected patients, $45 \%$ were preoperatively classified as having stage I, $18 \%$ stage II, $21 \%$ stage IIIa, and $7 \%$

Table 1. - Definition of cut-off limits from Fisher's exact test

\begin{tabular}{lcc}
\hline & With complications & Without complications \\
\hline$\leq x \lim$ & $\mathrm{A}$ & $\mathrm{B}$ \\
$>\mathrm{x} \lim$ & $\mathrm{C}$ & $\mathrm{D}$
\end{tabular}

Diagnostic gain is defined, using the cut-off limits (xlim) A, $\mathrm{B}, \mathrm{C}$ and $\mathrm{D}$, as $\mathrm{A} /(\mathrm{A}+\mathrm{B})-\mathrm{C} /(\mathrm{C}+\mathrm{D})$. stage IIIb. All nonresected patients had stage IIIb or IV disease. Patient characteristics, spirometric data, and exercise data are shown in table 2 .

The overall 30 day mortality rate was $9.3 \%$ (nine out of 97), and the mortality rate for the resected patients was $7.1 \%$ (six out of 85). The patients died for the following reasons: two patients from respiratory insufficiency (due to pulmonary dysfunction); two from excessive blood loss; two from heart failure; and one each from cor pulmonale; prolonged air leak; and cerebral infarction. The complications (including the fatal complications) were: bleeding $(n=21)$; atrial fibrillation $(n=18)$; wound infections $(n=12)$; lobar atelectasis $(n=11)$; respiratory insufficiency $(n=6)$; leak of the bronchus stump $(n=6)$; pneumonia $(n=6)$; bronchopleural fistula $(n=5)$; heart failure $(n=5)$; myocardial infarction $(n=2)$; and empyema $(n=2)$. Twenty nine patients had more than one complication. On the basis of the classification into the groups $\mathrm{C} 1$ and $\mathrm{C} 2$, patients who experienced postoperative complications were compared with patients without complications (table 3). Significantly lower preoperative performance was observed in most exercise parameters and all spirometric parameters in $\mathrm{C} 1$, but in the $\mathrm{C} 2$ group significantly lower values were found only in maximal work rate (WRmax) and $V^{\prime} \mathrm{CO}_{2}$, max. In both groups, WRmax showed the greatest differences between patients with and without complications. Table 4 shows the differences between patients who died of cardiopulmonary-related reasons $(n=5)$ and survivors $(n=92)$. Despite the small number of deaths, there were highly significant differences in $V^{\prime} \mathrm{O}_{2}$, max and WRmax, and no difference in spirometric values. Preoperative $V^{\prime} \mathrm{O}_{2}$, max and WRmax values were, as expected, very closely correlated $(\mathrm{r}=0.90, \mathrm{p}<0.00001$; Spearman), while there was a poor correlation between $\mathrm{FEV} 1$ and $V^{\prime} \mathrm{O}_{2}$, $\max (\mathrm{r}=0.46$; Spearman). Finally, logistic regression was used to determine which preoperative variables of lung function and exercise performance were predictors of postoperative complications. For the group with any possible complication $(\mathrm{C} 1)$, we found two variables that were predictive, $V^{\prime} \mathrm{O}_{2}$, max $\%$ pred $(\mathrm{p}=0.0007)$ and $\mathrm{FEV}_{1}(\mathrm{p}=0.0026)$, with a greater risk of developing complications with lower values. By using the logistic coefficients the risk

Table 2. - Patient characteristics and spirometric and exercise data

\begin{tabular}{|c|c|c|c|}
\hline & Mean & Range & SD \\
\hline Age & 64.3 & $38-80$ & 8.9 \\
\hline Body weight $\mathrm{kg}$ & 70.2 & $41-114$ & 12.2 \\
\hline Height $\mathrm{cm}$ & 171.3 & $145-188$ & 8.0 \\
\hline $\mathrm{BSA} \mathrm{m}^{2}$ & 1.82 & $1.35-2.23$ & 0.18 \\
\hline Smoking pack-yrs & 40.0 & $0-120$ & 22.7 \\
\hline FEV1 L & 2.20 & $1.11-3.66$ & 0.58 \\
\hline$\%$ pred & 74.8 & $31.3-131.2$ & 18.6 \\
\hline FVC L & 3.18 & $1.40-5.17$ & 0.72 \\
\hline$\%$ pred & 80.1 & $39.1-112.7$ & 14.9 \\
\hline$V^{\prime} \mathrm{O}_{2}, \max \mathrm{mL} \cdot \mathrm{min}^{-1}$ & 1376 & $707-2824$ & 412 \\
\hline$\%$ pred & 82.5 & $32.2-121.3$ & 18.8 \\
\hline$V^{\prime} \mathrm{E}, \max \mathrm{L}$ & 57.3 & $26.5-120.6$ & 16.4 \\
\hline WRmax W & 102.0 & $35-223$ & 34.9 \\
\hline
\end{tabular}

Values are means of 97 patients (67 males and 30 females). BSA: body surface area; FEV1: forced expiratory volume in one second; $\%$ pred: percentage of predicted value; FVC: forced vital capacity; $V^{\prime} \mathrm{O}_{2}$,max: oxygen uptake; $V$ 'E,max: ventilation; WRmax: maximum work rate. 
Table 3. - Comparison of variables between patients in group C1 (+; all complications) versus patients with no complications at all (-), and patients in group C2 (+; cardiopulmonary complications) versus patients without cardiopulmonary complications (-)

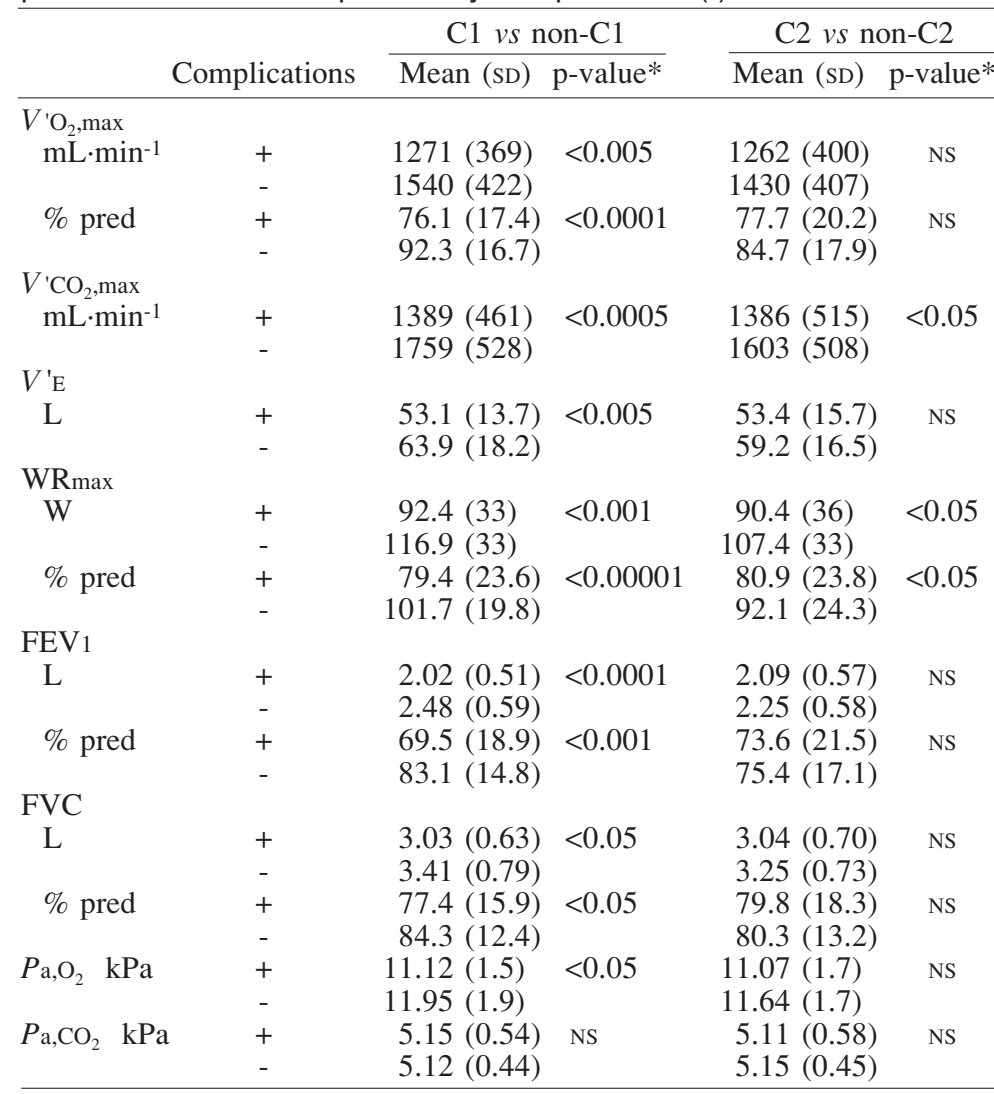

*: Mann-Whitney test. NS: nonsignificant. $V^{\prime} \mathrm{CO}_{2}$,max: carbon dioxide production; $\mathrm{Pa}, \mathrm{O}_{2}$ : arterial oxygen tension; $\mathrm{Pa}_{\mathrm{a}} \mathrm{CO}_{2}$ : arterial carbon dioxide tension. For further definitions see legend to table 2 .

Table 4. - Comparison of variables between patients with $(+)$ and without $(-)$ cardiopulmonary death

\begin{tabular}{|c|c|c|c|c|c|}
\hline \multirow{3}{*}{$\overline{V^{\prime} \mathrm{O}_{2}, \max }$} & \multirow[b]{2}{*}{$\%$ pred } & & \multicolumn{2}{|c|}{ Mean (SD) } & \multirow{2}{*}{$\begin{array}{c}\mathrm{p} \text {-value } \\
<0.001\end{array}$} \\
\hline & & + & 55.0 & (19.0) & \\
\hline & & - & 83.8 & (17.7) & \\
\hline \multirow[t]{2}{*}{ WRmax } & W & + & 71.6 & $(27.7)$ & $<0.05$ \\
\hline & & - & 103.6 & $(34.6)$ & \\
\hline \multirow[t]{2}{*}{ FEV1 } & $\%$ pred & + & 61.4 & $(24.7)$ & NS \\
\hline & & - & 75.5 & (18.1) & \\
\hline \multirow[t]{2}{*}{ FVC } & $\%$ pred & + & 69.54 & (28.73) & NS \\
\hline & & - & 80.68 & (13.88) & \\
\hline \multirow[t]{2}{*}{$P \mathrm{a}, \mathrm{O}_{2}$} & $\mathrm{kPa}$ & + & 9.75 & (1.65) & $<0.05$ \\
\hline & & - & 11.55 & (1.66) & \\
\hline
\end{tabular}

Statistical comparisons were made with the Mann-Whitney test. For definitions see legends to tables 2 and 3.

(R) of developing complications $(\mathrm{C} 1)$ can be calculated using the model:

\section{$7.911-0.052 \times V^{\prime} \mathrm{O}_{2}, \max \%$ pred-1.365 $\times \mathrm{FEV} 1=\ln (\mathrm{R} / 1-\mathrm{R})$}

This equation is depicted in graphical form in figure 1. For the group with only cardiopulmonary complications (C2), the logistic regression appeared with only one variable, WRmax $(p=0.028)$, predictive of postoperative complications, giving the model:

$$
0.794-0.016 \times W R \max =\ln (R / 1-R)
$$

This model is shown in figure 2. Only five patients died due to cardiopulmonary-related causes. Nevertheless, the logistic regression procedure showed a highly significant predictability of $V^{\prime} \mathrm{O}_{2}$, $\max (\mathrm{p}=0.0056)$, giving the model:

\section{$3.917-0.099 \times V^{\prime} \mathrm{O}_{2}, \max =\ln (\mathrm{R} / 1-\mathrm{R})$}

where $\mathrm{R}$ describes the risk of dying of cardiopulmonary-related causes (fig. 3). None of the variables age, sex, weight, height, body surface area, smoking history or cancer stage were significantly related to the risk of developing complications of any kind, or death. There was a trend towards relationships between cancer stage and age for all three groups of postoperative events, but these findings were not significant. No correlation was found between the rate of complication and the size of the resection.

Other studies have used $V^{\prime} \mathrm{O}_{2}$, max as a proportion of body mass $<20 \mathrm{~mL} \cdot \mathrm{kg}^{-1} \cdot \mathrm{min}^{-1}$ as the cut-off [23]. In the present study, all five cardiopulmonary deaths had a $V^{\prime} \mathrm{O}_{2}, \max <20$ $\mathrm{mL} \cdot \mathrm{kg}^{-1} \cdot \mathrm{min}^{-1}$, whereas $52 \%$ of the survivors were below this limit. We did not find a clear cut-off limit that could separate all the dying patients from all the survivors. We defined $V^{\prime} \mathrm{O}_{2}$, max $=12 \mathrm{~mL} \cdot \mathrm{kg}^{-1} \cdot \mathrm{min}^{-1}$ or $50 \%$ pred as the best limiters. Three of the five dying patients had a $V^{\prime} \mathrm{O}_{2}, \max <50 \%$ pred (sensitivity $=60 \%$ ), and 90 of the 92 patients not dying of cardiopulmonary complications were above this limit ( specificity $=98 \%$ ). This gives a diagnostic gain of $58 \%$ ( $\mathrm{p}=0.001$, Fisher's test). A WRmax of $70 \mathrm{~W}$ gave the best separation $(32 \%$ diagnostic gain, $\mathrm{p}=0.01$ ) of patients developing cardiopulmonary complications (fatal or not) from those with no such complications. Thus, 12 of the 31 patients with cardiopulmonary complications had a WRmax $<70 \mathrm{~W}$ (sensitivity $=39 \%$ ) and 57 of the 66 patients without cardiopulmonary complications had a $\mathrm{WRmax}>70 \mathrm{~W}$ (specificity $=83 \%$ ).

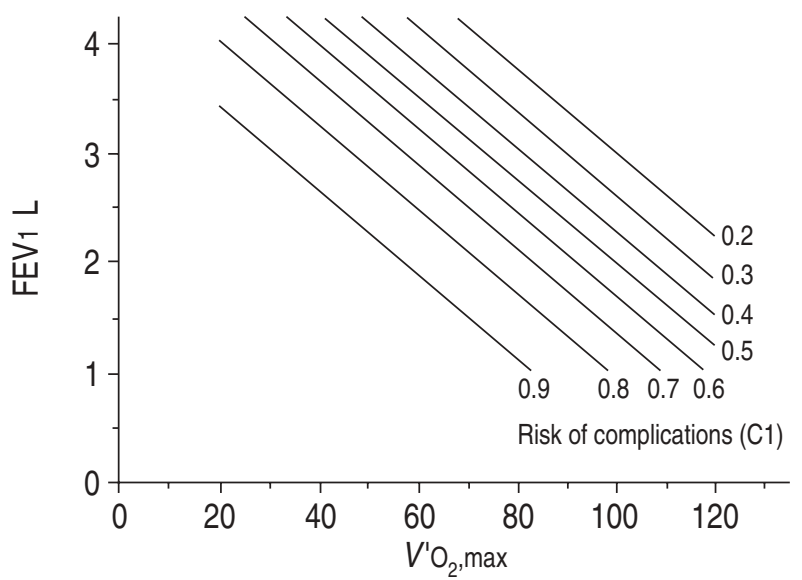

Fig. 1. - The relationship between forced expiratory volume in one second $(\mathrm{FEV} 1)$, oxygen uptake $\left(V^{\prime} \mathrm{O}_{2}, \max \right)$, and the risk of development of complications of any kind. The point of intersection between the measured FEV1 and $V^{\prime} \mathrm{O}_{2}$,max indicate the risk. Relationships were calculated by logistic regression. 


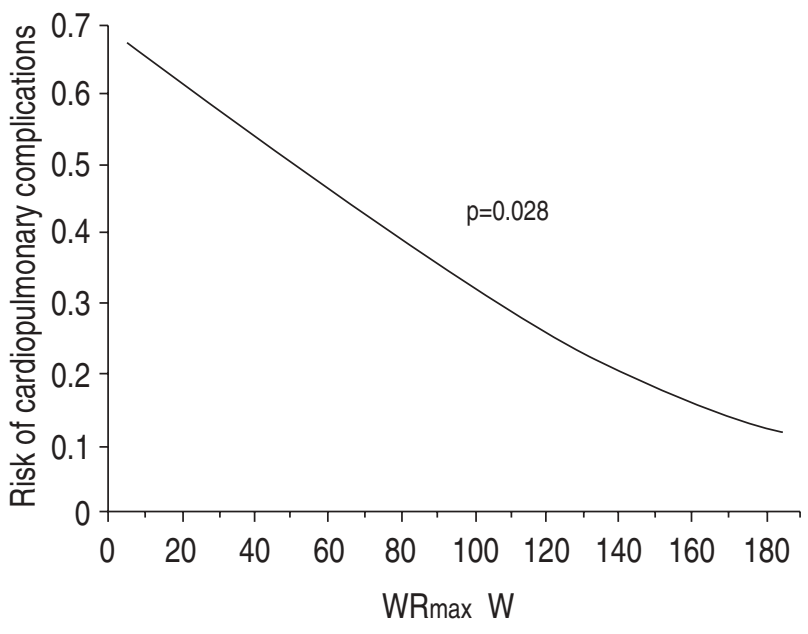

Fig. 2. - The relationship between maximum work rate (WRmax) and the risk of development of cardiopulmonary complications. The relationship was calculated by logistic regression.

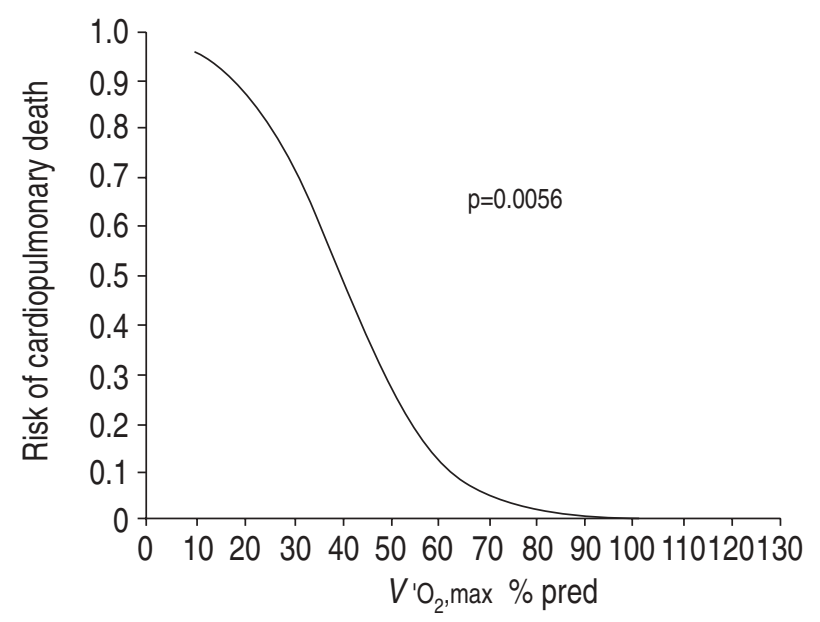

Fig. 3. - The relationship between oxygen uptake $\left(V^{\prime} \mathrm{O}_{2}, \max \right)$ ad the risk of cardiopulmonary death. The relationship was calculated by logistic regression. \% pred: percentage of predicted value.

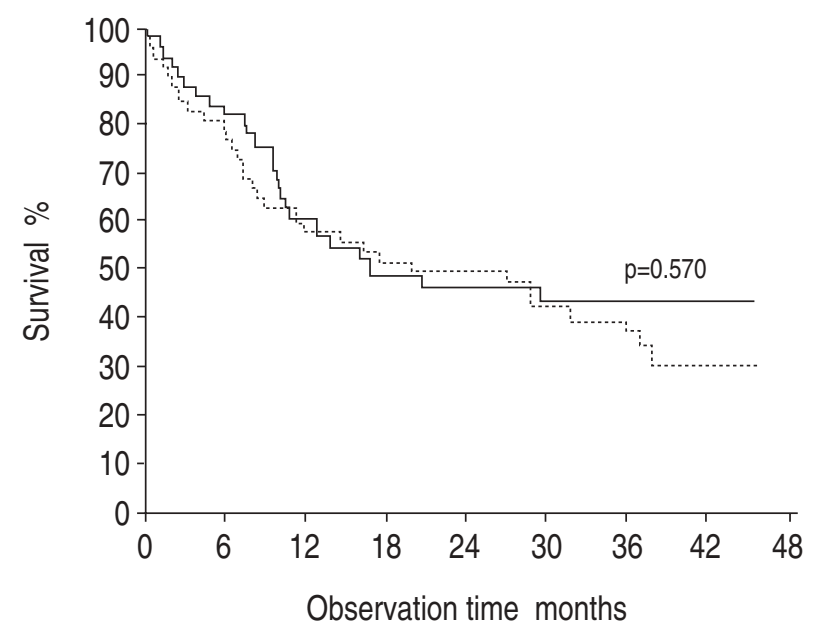

Fig. 4. - Long-term survival of the patients divided according to a forced expiratory volume in one second (FEV1) of $>74 \%$ predicted $(-)$, or $<74 \%$ pred ( $. \cdots . . .$.$) , calculated by Kaplan-Meier, log-rank.$

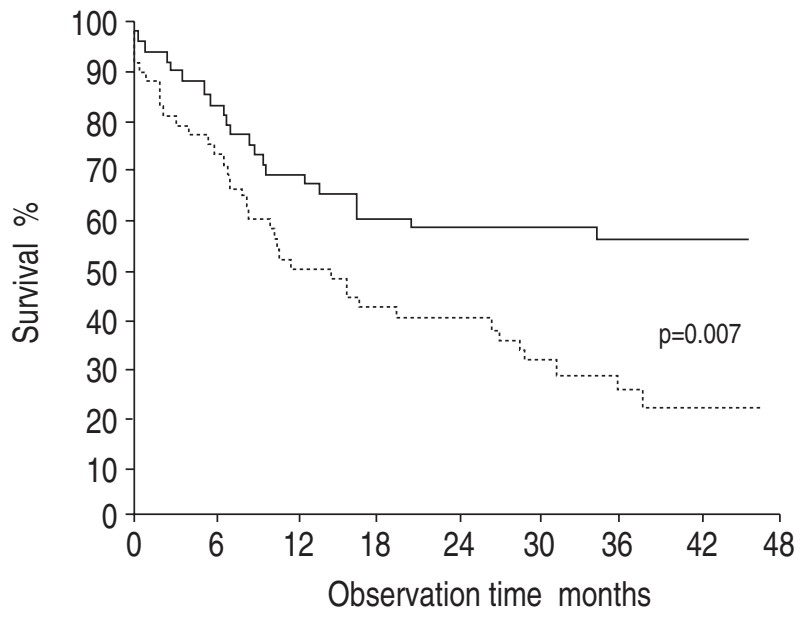

Fig. 5. - Long-term survival of the patients divided according to an oxygen uptake $\left(V^{\prime} \mathrm{O}_{2}, \mathrm{max}\right)$ of $>1,345 \mathrm{~mL} \cdot \mathrm{min}^{-1}(-)$ or $<1,345 \mathrm{~mL} \cdot \mathrm{min}^{-1}$ $($..... ) at standard temperature and pressure in the absence of water vapour, calculated by Kaplan-Meier, log-rank.

The above analyses were performed on the 30 day mortality. To evaluate the influence of preoperative spirometric and exercise variables on long-term survival, Kaplan-Meier survival curves were plotted. There were no corrections for cause of death. The following variables were correlated to long-term survival: $V^{\prime} \mathrm{O}_{2}$, max ( $\mathrm{p}=0.007)$, WRmax $(\mathrm{p}=0.03)$, and $P \mathrm{a}, \mathrm{CO}_{2}(\mathrm{p}=0.003)$, while neither FEV1 nor FVC separated patients with regard to long-term survival. Figures 4 and 5 show survival of the patients according to $\mathrm{FEV} 1$ and $V^{\prime} \mathrm{O}_{2}$, max, respectively.

\section{Discussion}

The results of studies of the usefulness of exercise testing in preoperative assessment of patients with lung cancer are conflicting. These studies differ widely in design, number of participating patients, registration of complications and, particularly, in statistical methods. In the study of COLMAN et al. [27], low FEV1 and VC were found to have prognostic significance for the development of postoperative morbidity and mortality, while poor exercise performance did not. The study in many ways resembles the present study, and the discrepancy in the predictability of exercise variables could be explained by the fact that: 1) the number of patients that participated in the study of COLMAN et al. [27] was half that of the present study; 2) some patients may have been submaximally tested by COLMAN et al. [27], as no objective criteria for actual physiological maxima were mentioned; and 3) no information was given about $V^{\prime} \mathrm{O}_{2}$, max as a percentage of predicted values, or corrected for body weight. In the study of MARKos et al. [12], only the degree of desaturation during work and FEV1,ppo were predictive of cardiopulmonary morbidity. Again the observed values of $V^{\prime} \mathrm{O}_{2}$, max during maximal work in this paper were clearly lower than in the present study (WRmax $67 \mathrm{vs}$ $81 \%$ pred, respectively, for patients with complications), which indicate either that the patients in the work of MARKos et al. [12] might not have exercised to a physiological maximum, or that the exclusion procedure used 
in the present study for patients not considered able to complete a maximal ergometer exercise test was responsible for the higher values. All patients, with one exception, in the study of MARKOS et al. [12] over a 16 months inclusion period were included, and there was no attempt to exclude patients not likely to be able to perform a physiological maximal exercise test (e.g. patients with muscle or joint pains, or severely weakened patients). These conditions could account for some of the discrepancy between the present study and other papers. Other studies support the present results [16, 21-26].

The 97 patients in the present study represent one of the largest numbers of patients with bronchogenic carcinoma to have participated in studies of exercise tests as preoperative evaluation. In order to compare the present study with others, we intended to apply all previously used statistical methods to the present data, and we registered any complication and subsequently analysed subgroups of patients with or without cardiopulmonary-related complications. It is evident that both the nonparametric statistics (table 3 and 4) and the logistic regression analyses (figs. 1, 2, and 3 ) give the same indication. Both exercise variables and spirometric variables are predictive of complications, including those related to technical procedures, while only exercise variables are predictive of cardiopulmonary-related complications, or death from cardiopulmonary causes. Furthermore, Kaplan-Meier survival curves showed that exercise variables were correlated to long-term survival. The risk for each individual can be estimated by using the nomograms in figures 1,2 , and 3 . Such calculations must be applied in daily clinical routine with great caution, because development of complications after resection for lung cancer is a multifactorial occurrence. They could, however, be a useful tool, among others, in the preoperative risk estimation of an individual patient with questionable physiological operability.

We defined the cardiopulmonary complications as: respiratory insufficiency; prolonged mechanical ventilation; heart failure; myocardial infarction; pneumonia; and lobar atelectasis. Arrhythmias, of which atrial fibrillation is by far the commonest, were not included in this group, because they are very common and are not normally related to other cardiopulmonary complications. Furthermore, the management of this condition is without clinical problems. The results of ECG monitoring and its predictability with regard to postoperative cardiac complication will be published elsewhere. In exercise testing, both the ventilatory and cardiovascular systems are tested, which can explain the observation that exercise variables are predictive of cardiopulmonary complications and deaths. It is much more difficult to give a causal explanation of the results showing that both spirometric and exercise variables are predictive of complications related to the technical procedure. One could speculate about a decreased oxygen tension in the pulmonary tissue due to diminished cardiopulmonary function. This again could cause increased risk of infection or development of necrosis, or decreased healing capacity. This is, of course, pure speculation without scientific evidence.

The overall 30 day mortality rate in the present study was $9.3 \%$, and $7.1 \%$ for the resected patients. This is higher than in some series, where the reported 30 day mortality rates range $0.6-5 \%$ [18-20], depending on the surgical procedure. It may be as high as $17 \%$ after angioplastic procedure [35]. None of our patients had modificational surgical procedures. In the interpretation of our results it is important to reflect on the initial procedure of selection. Patients with low ventilatory capacity were not included in the study, as they were not physiologically operable. This probably reduces the probability of finding a high predictability of complications from variables such as FEV1 and FVC. However, it was considered unethical to depart from the generally accepted criteria for operability.

In daily clinic, most patients with ischaemic and valvular heart disease are able to perform a maximal exercise test with little increased risk. This test is, in fact, one of the most important noninvasive diagnostic methods in patients with heart disease. Patients who were not interested in participating in the study could be exercise tested, if this was an accepted preoperative test. If these two groups were included in exercise evaluation, $83 \%$ of the operable patients in our study could undergo an exercise test.

Patients with untreated pulmonary carcinoma have a very poor prognosis. If the patient has a resectable tumour, only high probability of postoperative death or severe disability justify denying the potential survival benefit brought on by surgery. As a consequence of this, the recommendations shown below are proposed on the basis of the mortality analyses. Although the number of cardiopulmonary deaths was rather low, the results were highly significant, and form the best available basis from which to make decisions. However, in every case it is necessary to discuss the potential risks, not only of dying, but also of developing other nonfatal complications. The results of the analyses of cardiopulmonary complications could help the physician in this guidance.

On the basis of other investigations and the present study, we would suggest that the recommendations described in table 5 for preoperative evaluation of patients with bronchogenic carcinoma should be followed. These criteria are based only on the results of the cardiopulmonary complications and deaths. If the criteria in one step are met, the patient is operable, and no further investigations are made. If not, one continues to the next step. The first two steps are well-known criteria and we have

Table 5. - Stepwise preoperative evaluation: recommendations

\begin{tabular}{ll}
\hline Step & Parameters \\
\hline 1) Spirometry and & FEV1 $>2 \mathrm{~L}$ \\
diffusion capacity & FEV1 or $T \mathrm{~L}, \mathrm{CO}>60 \%$ pred, or if \\
& FEV1/FVC $<85 \%$ pred, maximal \\
& broncholytic treatment is given, \\
and the measurements are repeated \\
2) Regional pulmonary & FEV1,ppo $>800 \mathrm{~mL}$, or FEV1,ppo \\
perfusion & $>40 \%$ pred \\
3) Exercise test & $V^{\prime} \mathrm{O}_{2}$, max $<50 \%$ pred: marked risk of \\
& cardiopulmonary death \\
& WRmax $<70 \mathrm{~W}$ : risk of cardio- \\
& pulmonary complications
\end{tabular}

If the criteria in one step are met, the patients is operable; if not, continue to the next step. The risk for the individual patient can be estimated using the nomograms in figures 1,2 and 3 . FEV1: forced expiratory volume in one second; $T \mathrm{~L}, \mathrm{CO}$ : transfer factor of the lung for carbon monoxide; \% pred: percentage of predictd value; FVC: forced vital capacity; FEV1,ppo: predicted postoperative FEV1. 
introduced the exercise criteria as Step 3. Thus, if these criteria are followed, in the best case we will find some patients meeting the exercise demands, who earlier would have been judged inoperable. In the worst case we will operate the same number of patients as now. We recommend that these criteria should be checked in a larger scale prospective study.

In conclusion, exercise testing is useful in evaluating selected patients with nonmetastatic bronchogenic carcinoma. A combination of ventilatory variables and exercise test variables are proposed as preoperative criteria for operability.

\section{References}

1. Olsen JH. Epidemiology of lung cancer. Eur Respir Mon 1995; 1: 1-17.

2. Drings P, Vogt-Moykopf I. Pre-operative assessment of patients undergoing surgery for bronchial carcinoma. European Society of Pneumology 1986; 10: 7-11.

3. Zibrak JD, O'Donnel CR, Marton K. Indications for pulmonary function testing. Ann Intern Med 1990; 112: 763-771.

4. Marshall MC, Olsen GN. The physiologic evaluation of the lung resection candidate. Clin Chest Med 1993; 14: 305-319.

5. Gilbreth EM, Wiesman IM. Role of exercise stress testing in preoperative evaluation of patients for lung resection. Clin Chest Med 1994; 15: 389-403.

6. Dunn WF, Scanlon PD. Preoperative pulmonary function testing for patients with lung cancer. Mayo Clin Proc 1993; 68: 371-377.

7. Ali MK, Ewer MS, Atallah MR, et al. Regional and overall pulmonary function changes in lung cancer. Correlations with tumor stage, extent of pulmonary resection, and patient survival. I Thorac Cardiovasc Surg 1983; 86: 1-8.

8. Corris PA, Ellis DA, Hawkins T, Gibson GJ. Use of radionuclide scanning in the preoperative estimation of pulmonary function after pneumonectomy. Thorax 1987; 42: 285-291.

9. Cordiner A, De Carlo F, De Gennaro R, Pau F, Flore F. Prediction of postoperative pulmonary function following thoracic surgery for bronchial carcinoma. Angiology 1991; 42: 985-989.

10. Olsen GN, Block AJ, Tobias JA. Prediction of postpneumonectomy pulmonary function using quantitative macroaggregate lung scanning. Chest 1974; 66: 13-16.

11. Wernly JA, DeMeester TR, Kirchner PT, Myerowitz PD, Oxford DE, Golomb HM. Clinical value of quantitative ventilation-perfusion lung scans in the surgical management of bronchogenic carcinoma. J Thorac Cardiovasc Surg 1980; 80: 535-543.

12. Markos J, Mullan BP, Hillman DR, et al. Preoperative assessment as a predictor of mortality and morbidity after lung resection. Am Rev Respir Dis 1989; 139: 902-910.

13. Anderson R, Arentzen C. Carcinoma of the lung. Surg Clin North Am 1980: 60: 793-814.

14. Boysen PG, Harris JO, Block AJ, Olsen GN. Prospective evaluation for pneumonectomy using perfusion scanning: follow-up beyond one year. Chest 1981; 80: 163-166.

15. Gass GD, Olsen GN. Preoperative pulmonary function testing to predict postoperative morbidity and mortality. Chest 1986; 89: 127-135.
16. Nakagawa K, Nakahara K, Miyoshi S, Kawashima Y. Oxygen transport during incremental exercise load as a predictor of operative risk in lung cancer patients. Chest 1992; 101: 1369-1375.

17. Drings P. Preoperative assessment of lung cancer. Chest 1989; 96: 42S-44S.

18. Miller JI. Physiologic evaluation of pulmonary function in the candidate for lung resection. J Thorac Cardiovasc Surg 1993; 105: 347-352.

19. Damhuis RAM, Schütte PR. Resection rates and postoperative mortality in 7,899 patients with lung cancer. Eur Respir J 1996; 9: 7-10.

20. Kadri MA, Dussek JE. Survival and prognosis following resection of primary non-small cell bronchogenic carcinoma. Eur J Cardiothorac Surg 1991: 5: 132-136.

21. Eugene J, Brown SE, Light RW, Milne NE, Stemmer EA. Maximum oxygen consumption: a physiologic guide to pulmonary resection. Surg Form 1982; 33: 260-262.

22. Morice RC, Peters EJ, Ryan MB, Putnam JB, Ali MK, Roth JA. Exercise testing in the evaluation of patients at high risk for complications from lung resection. Chest 1992; 101: 356-361.

23. Bechard D, Wetstein L. Assessment of exercise oxygen consumption as preoperative criterion for lung resection. Ann Thorac Surg 1987; 44: 344-349.

24. Smith TP, Kinasewitz GT, Tucker WY, Spillers WP, George RB. Exercise capacity as a predictor of postthoracotomy morbidity. Am Rev Respir Dis 1984; 129: 730-734.

25. Epstein SK, Faling LJ, Daly BD, Celli BR. Predicting complications after pulmonary resection. Preoperative exercise testing $v s$ a multifactorial cardiopulmonary risk index. Chest 1993; 104: 694-700.

26. Dales RE, Dionne G, Leech JA, Lunau M, Schweitzer I. Preoperative prediction of pulmonary complications following thoracic surgery. Chest 1993; 104: 155-159.

27. Colman NC, Schraufnagel DE, Rivington RN, Pardy RL. Exercise testing in evaluation of patients for lung resection. Am Rev Respir Dis 1982; 125: 604-606.

28. Miyoshi S, Nakahara K, Ohno K, Monden Y, Kawashima Y. Exercise tolerance test in lung cancer patients: the relationship between exercise capacity and post-thoracotomy hospital mortality. Ann Thorac Surg 1987; 44: 487490.

29. Holden DA, Rice TW, Stelmach K, Meeker DP. Exercise testing, 6-min walk, and stair climb in the evaluation of patients at high risk for pulmonary resection. Chest 1992; 102: 1774-1779.

30. Beaver WL, Wasserman K, Whipp BJ. A new method for detecting the anaerobic threshold by gas exchange. J Appl Physiol 1986; 60: 2020-2027.

31. Wasserman K, Hansen J, Sue D, Whipp B. Principles of exercise testing and interpretation. Philadelphia, Lea and Febiger, 1987.

32. Zavala DC. Manual on exercise testing: a training handbook. Press of The University of Iowa, 1987.

33. Spirometry. A recommendation. Copenhagen, Danish Pulmonary Society, 1986.

34. Pocock S. Clinical Trials. A Practical Approach. Chichester, John Wiley and Sons, 1995.

35. Vogt-Moykopf I, Fritz T, Meyer G. Bronchoplastic and angioplastic operations in bronchial carcinoma: longterm results of a retrospective analysis from 1973 to 1983. Int Surg 1986; 71: 211-220. 